\title{
Return-to-Work Self-Efficacy: Development and Validation of a Scale in Claimants with Musculoskeletal Disorders
}

\author{
Sandra Brouwer · Renée-Louise Franche • \\ Sheilah Hogg-Johnson · Hyunmi Lee • \\ Niklas Krause • William S. Shaw
}

Published online: 24 September 2010

(c) The Author(s) 2010. This article is published with open access at Springerlink.com

\begin{abstract}
Introduction We report on the development and validation of a 10-item scale assessing self-efficacy within the return-to-work context, the Return-to-Work Self-Efficacy (RTWSE) scale. Methods Lost-time claimants completed a telephone survey 1 month $(n=632)$ and 6 months $(n=446)$ after a work-related musculoskeletal injury. Exploratory (Varimax and Promax rotation) and confirmatory factor analyses of self-efficacy items were conducted with two separate subsamples at both time points. Construct validity was examined by comparing scale measurements and theoretically derived constructs, and the phase specificity of RTWSE was studied by examining changes in strength of relationships between the RTWSE Subscales and the other constructs at both time measures. Results Factor analyses supported three underlying factors: (1) Obtaining help from supervisor, (2) Coping with pain
\end{abstract}

\section{S. Brouwer $(\square)$}

Department of Health Sciences, Work \& Health,

University Medical Center Groningen, University of Groningen,

Antonius Deusinglaan 1, Building 3217, Room 620,

9713 AV Groningen, The Netherlands

e-mail: sandra.brouwer@med.umcg.nl

R.-L. Franche

Occupational Health and Safety Agency for Healthcare,

Vancouver, BC, Canada

R.-L. Franche · S. Hogg-Johnson

Dalla Lana School of Public Health, Faculty of Medicine,

University of Toronto, Toronto, ON, Canada

R.-L. Franche

Faculty of Health Sciences, Simon Fraser University,

Vancouver, BC, Canada

R.-L. Franche · S. Hogg-Johnson · H. Lee

Institute for Work \& Health, Toronto, ON, Canada
(3) Obtaining help from co-workers. Internal consistency (alpha) for the three subscales ranged from 0.66 to 0.93 . The total variance explained was $68 \%$ at 1 -month followup and $76 \%$ at 6-month follow-up. Confirmatory factor analyses had satisfactory fit indices to confirm the initial model. With regard to construct validity: relationships of RTWSE with depressive symptoms, fear-avoidance, pain, and general health, were generally in the hypothesized direction. However, the hypothesis that less advanced stages of change on the Readiness for RTW scale would be associated with lower RTWSE could not be completely confirmed: on all RTWSE subscales, RTWSE decreased significantly for a subset of participants who started working again. Moreover, only Pain RTWSE was significantly associated with RTW status and duration of work disability. With regard to the phase specificity, the strength

\author{
R.-L. Franche \\ School of Population and Public Health, \\ University of British Columbia, Vancouver, BC, Canada \\ N. Krause \\ Division of Occupational and Environmental Medicine, \\ Department of Medicine, University of California, \\ San Francisco, CA, USA \\ W. S. Shaw \\ Liberty Mutual Research Institute for Safety, \\ Hopkinton, MA, USA \\ W. S. Shaw \\ Department of Family Medicine \& Community Health, \\ University of Massachusetts Medical School, \\ Worcester, MA, USA
}


of association between RTWSE and other constructs was stronger at 6 months post-injury compared to 1 month post-injury. Conclusions A final 10-item version of the RTWSE has adequate internal consistency and validity to assess the confidence of injured workers to obtain help from supervisor and co-workers and to cope with pain. With regard to phase specificity, stronger associations between RTWSE and other constructs at 6-month followup suggest that the association between these psychological constructs consolidates over time after the disruptive event of the injury.

Keywords Self-efficacy · Return-to-Work · Validity · Questionnaire

\section{Introduction}

Return-to-work (RTW) has been defined as a health-related behavior involving elements of motivation and self-management, influenced by physical, psychological, and social factors [1].

One theoretical model that has embraced a behavioral formulation of RTW is the Readiness for Return-to-Work (RRTW) Model [2]. This model focuses on the interpersonal and systemic aspects of work disability, and combines elements from existing theories: the Readiness for Change Model that describes stages in the process of adopting healthy behavior [3], and the Phase Model of Occupational Disability that describes temporal shifts in disability-related beliefs and behaviors [4, 5]. The Readiness for Change Model [3, 6, 7] addresses the motivational factors contributing to and maintaining behavior change. This model proposes that relative to a given behavior change, individuals will find themselves at a certain motivational stage. The model has received strong empirical support and it is particularly well validated in the area of health-risk behaviors [7-9].

The Phase Model of Occupational Disability stresses the phase specificity of risk factors: Physical and injury factors are determining predictors of disability in the acute phase (up to 1 month), whereas psychosocial factors have stronger predictive value in the subacute (2-3 months) and chronic phases of disability (more than 3 months) [2, 10, 11].

The application of both models to the behavior of returning to work has been considered by Franche and Krause [2]. The RRTW model proposes that relative to a given behavior, individuals progress from one stage to the other. Five stages of change are proposed: Precontemplation, Contemplation, Preparation-for-Action, Action, and Maintenance. These stages have been described in detail previously as they apply to RTW [2, 12]. In the RRTW model each stage is determined by three dimensions of change: individuals' decisional balance, self-efficacy, and change processes about RTW. For instance-and related to this study-self-efficacy is hypothesized to increase as an individual progresses to more advanced stages of Readiness [2].

A first step in the application of the RRTW Model consists of the development and validation of the RRTW Scale [12]. The next step in the application of the RRTW Model is the development and validation of scales measuring the three determinants of the change stage: decisional balance, self-efficacy, and change processes [12]. The main goal of this current study is the development and validation of the RTWSE Scale.

According to Bandura's social cognitive theory [13], self-efficacy is the prime factor influencing behavior and has been defined as "people's beliefs in their capabilities to organize and execute the courses of action required to produce given attainments." Bandura's self-efficacy theory asserts that psychological treatments facilitate behavior change by creating and strengthening expectations of selfefficacy [14]. Several authors emphasize the role of selfefficacy in the RTW process [15-17] and in the work disability prevention framework [17-19]; however, a comprehensive understanding of the role of self-efficacy on development and duration of work disability is still lacking. In patients having suffered a cardiac event, self-efficacy measured early in the recovery process was the strongest predictor of 1-month self-reported full-time or part-time RTW, independent of disease severity, age, job classification, and gender [20]. Patients with high self-efficacy levels returned to work earlier than those with low self-efficacy levels [20]. Labriola et al. [17] found that self-efficacy scores were significantly lower in workers with sickness absence as opposed to workers who were working. Brouwer et al. [21] found a significant association between selfefficacy and the time to RTW in workers sick-listed for a duration of 6-12 weeks in a 10-month follow-up study. The estimated hazard (HR) of a shorter time to RTW was 1.42 times higher in individuals who reported a higher selfefficacy level compared to those with a lower self-efficacy level.

These results underscore the importance of increasing workers' self-efficacy in the recovery process. Conflicting findings were found in a study of Labriola et al. [17] and of Lötters et al. [22]. Labriola et al. [17] found no statistically significant association for self-efficacy with later onset of sickness absence or with RTW in workers with sickness absence for three weeks or more. In a 1-year follow-up study of Lötters et al. [22], depressive symptoms and poor physical health, but not self-efficacy, were associated with duration of lost-time benefits in workers with musculoskeletal disorders four to five weeks postinjury. 
Differences in populations, measurements, and outcomes make it difficult to compare results of these studies and to explain the conflicting findings. However, one of the main limitations of the above studies and a possible reason for conflicting findings is the absence of a self-efficacy measurement specific to RTW. Indeed, there is a need to develop and validate a measurement of self-efficacy for RTW, as no self-efficacy questionnaire has been validated within the RTW context. Furthermore, differences in results might be explained by the progressing phases of disability and the related "phase specificity" of risk factors, i.e. the impact of risk factors which may vary across different phases of the disablement process [4, 10-24]. Dasinger et al. [23] demonstrated that physical job and injury factors have a time-varying impact on duration of disability. They found in a study among workers' compensation claimants that previous back injury predicts shorter disability only during the subacute/chronic disability phases. Krause et al. [10] found in their study that high job control and supervisor support are only associated with higher RTW rates during the subacute/chronic disability phase starting 30 days after injury. Up to now, the phase specific impact of self-efficacy on the time to RTW has not been investigated but is of interest.

The aim of the present study was to develop and validate a scale that would measure RTWSE as self-reported by injured workers with back and upper extremity (UE) musculoskeletal (MSK) disorders, and to examine the phase specific effects of self-efficacy. To accomplish this aim, based on a qualitative study in back-injured workers of Shaw and Huang [1], the authors complied a 10-item RTWSE scale with the goal of assessing self-efficacy of workers to return to work within two conceptual domains:

(1) controlling pain at work and (2) obtaining help.

The new adapted scale was validated by conducting factor analyses (exploratory and confirmatory) with separate samples (cross-validation) and by exploring its construct validity-that is, correlations expected based on theory-between scale measurements and theoretically derived constructs. A correlation structure that supports the hypothesized pattern contributes evidence of construct validity [25]. To investigate stage specificity of the RTWSE scale, changes over time as to strength of the association with self-efficacy and other theoretically derived constructs, factor analyses and construct validity at 1-month follow-up (T1) and 6-month follow-up (T2) were reported.

\section{Hypotheses}

The constructs used to establish the scale's construct validity are based on the RRTW model.
Primary Hypotheses

Low self-efficacy will be associated with:

1. Less advanced stages of change: The RRTW model proposes that, relative to a given behavior, individuals progress from one stage to the other, and that each stage is determined by individuals' decisional balance, self-efficacy, and change processes concerning RTW. Less advanced stages of change are related to lower self-efficacy [2].

2. Less optimal RTW status: Previous research with work-disabled workers indicates that self-efficacy is significantly associated with work status. Lower selfefficacy scores are associated with sickness absence compared to a working subsample [17], and a high level of self-efficacy is positively associated with RTW [12, 20].

3. Lower perception of social support from supervisor and co-workers: Workers feel more confident to return to work if employers demonstrate support, and if the injured workers can request help from co-workers $[1,10,24,26]$. These workers are likely to be more deeply embedded in the team's social structure and may feel sufficiently supported so that they can ask for help from their co-workers [27].

4. Within the Phase Model of Occupational Disability, psychosocial factors have been described as having stronger predictive value of disability in the subacute and chronic phases $[2,10,11]$. With regard to this phase specificity of risk factors $[4,10,24]$, the strength of relationships between self-efficacy-as a psychosocial factor-measured with the RTWSE Scale and the other constructs will be stronger 6 months post-injury (chronic phase) as compared to 1 month (acute phase) post-injury.

\section{Secondary Hypotheses}

Low self-efficacy will be associated with:

1. More impaired levels of physical health, mental health (including depressive symptoms), and functional ability: Previous research on Readiness for Self-management of Pain shows that individuals in less advanced stages of change report higher levels of pain, and higher levels of depressive symptomatology [28]. Depressive symptomatology has a significant impact on selfefficacy in general [29] and on return-to-work rates [2].

2. Higher levels of pain: Previous research on Readiness for Self-management of Pain shows that individuals in less advanced stages of change report more severe pain [28]. 


\section{Methods}

\section{Study Design}

This study was conducted within the sampling frame of the RRTW cohort $[12,30]$, a prospective cohort study of lost-time claimants with work-related back or UE MSK disorders, who were recruited in cooperation with the Workplace Safety and Insurance Board (WSIB) of Ontario, Canada. A detailed description of the participant recruitment procedure has been published elsewhere [12]. Data were obtained from two separate sources: participant structured interviews and the WSIB administrative database. Participants were interviewed by phone 1,6 , 12 , and 24 months post-injury. For this study, the selfreport data were obtained from 1-month and 6-month interviews, with the socio-demographic data being collected from the 1-month interview. Participants provided information on RTW experiences, health outcome, and work characteristics. Routinely captured claim information, such as time receiving wage replacement benefits and claim status, was extracted from the WSIB database and linked to the interview data when written consent for linkage was provided by the participant. The study was approved by the University of Toronto Ethics Review Board.

\section{Measurements}

\section{Return-to-Work Self-Efficacy Scale}

A group composed of two clinical psychologists, a psychometrist, and a graduate student in community research, all with expertise in occupational health, developed the original pool of items for the scale. Eight items of the 10-item RTWSE Scale originate from scales developed by Shaw and Huang [1]: three items from the subdomain "ability to cope with pain" (pain-tolerate, pain-prevent, pain-manage), five items from the subdomain "obtaining help from others," (three items from the content area of the "help from supervisor" and two items within the content area of "help from co-workers"). Furthermore, two items of self-efficacy for RTW were added: one additional item within the content area of the supervisor and one item with regard to general self-efficacy. The format of the items was based on the one used in the Arthritis Self-efficacy Scale [31]. There were five response options; for each item participants were asked to rate their confidence with regard to each item on a five-point scale $(0=$ not at all certain, $4=$ completely certain). The higher the score on the Self-efficacy for RTW Scale, the higher someone's self-efficacy.

\section{Socio-Demographic Characteristics}

Age, gender level of education and annual personal income were assessed by self-report.

\section{Readiness for Return-to-Work}

Stages of Change Stages of change were assessed with the RRTW Scale, a 22-item measurement with 13 items for Non-working individuals, and 9 items for Working individuals (those people who have returned to work). The items in this scale reflect closely but not perfectly the stages described in the theoretical framework of the RRTW model [2]: Non-working individuals are in the first stages of the RRTW model (Precontemplation, Contemplation, Prepared-for-Action Behavioral, Prepared-for-Action Selfevaluative). Working individuals are found in two stages of Maintenance (Uncertain Maintenance and Proactive Maintenance). Previous research has had mixed results concerning the presence of the five mutually exclusive stages defined by Prochaska [39, 40]. In earlier empirical work with the RRTW cohort, some difference in stage structure were found. The Prepared-for-Action stage split into two separate factors: The action stage seemed to be interpreted as a maintenance stage, while the maintenance stage split further into two different factors as well. The psychometric properties of the RRTW Scale in our cohort confirmed good internal (exploratory and confirmatory factor analyses) and external validity (construct validity) [12].

One limitation of the current analysis is that while the full scale was completed by a sample at 1-month followup, only 8 of the 13 items for Non-working participants and 7 of the 9 items for Working participants were included due to pressure to shorten the length of the questionnaire. To confirm that this version of the RRTW Scale at 6-month follow-up is similar to the version at 1-month follow-up, we correlated the results of both versions at 1-month data for each dimension separately. For four of the dimensions (Precontemplation, Contemplation, Prepared-for-Action Behavioral and Proactive Maintenance) the correlation was 1.000. For the dimension Uncertain Maintenance a correlation of 0.904 was found. And for the dimension Preparedfor-Action Self-evaluative, a correlation of 0.72 was found. Hence, the pattern of correlations suggested a strong correspondence between the two versions of the scale.

\section{RTW Status}

At baseline, four mutually exclusive RTW status groups were constructed, based on the workers' responses to the following yes/no questions: "Have you gone back to work 
at any point since your injury (including part-time or modified work)?" and "Are you currently working at any job right now?" The four groups were: (1) sustained first return to work (RTW-S), (2) return to work with recurrence(s) of work absence and working at time of interview (RTW-R working), (3) return to work with recurrence(s) of work absence and not working at time of interview (RTW$\mathrm{R}$ not working), and (4) no return to work (No RTW). In the analyses, we collapsed the two RTW groups with recurrence(s) groups into one group (RTW-R). RTW status was assessed at each follow-up.

\section{Work Absence Duration and Compensation Characteristics}

The number of work days missed due to the injury was collected at the time of interview by self-report. In addition, the number of calendar days receiving wage replacement benefits ( $100 \%$ benefits) was obtained from the WSIB administrative database only for participants who provided written consent for linkage of questionnaire data and WSIB data.

\section{Social Support at Work}

Supervisor Support The Supervisor Support after Injury Scale assessed the quality of supervisor interaction with the injured worker with respect to the injury on a scale from 1 (strongly disagree) to 5 (strongly agree). This scale was based on items from a previously used questionnaire [37] and also included items developed for the purpose of this study by a clinical psychologist, an organizational psychologist, a psychometrist, and a graduate student in community health, reflecting the concept of legitimacy [38], that is, the degree to which an injured worker feels believed by others regarding the authenticity of their injury and of their symptoms. Legitimacy is of particular relevance to injuries and illnesses that involve work absences and are "invisible," such as back pain. Principal component analysis with our baseline sample revealed a single factor that explained $58 \%$ of the variance of this 7 -item scale, that is, supervisor $(\alpha=0.88)$ [unpublished analyses].

\section{Health Outcome}

Current pain level was assessed with two items from the intensity subscale of the Von Korff Pain Scale [32]. Participants were asked to rate their pain from their workplace injury "right now" on a scale from 0 (no pain) to 10 (pain as bad as could be) at that moment in time, as well as their usual level of pain over the past month. Both items were highly correlated $(R=0.67, P<0.01)$ and only the item on "pain right now" was used for the current analyses.
Depression The 20-item Center for Epidemiologic Studies Depression (CES-D) [33] Scale was used to measure depressive symptoms. The items reported the frequency of occurrence of symptoms in the past week on a four-point rating scale ranging from "rarely or none of the time" ( $<1$ day) to "most of the time" (5-7 days). The scores ranged from 0 to 60 with a higher score denoting more depressive symptoms. CES-D scores $\geq 16$ are indicative of individuals at risk for clinical depression [33]. The internal consistency was 0.92 , measured in the baseline sample [30].

General health was assessed with the 12-Item Shortform Health Survey (SF-12), a 12-item version of the SF-36 [34] to measure physical (PCS12) and mental (MCS12) health. The scores ranged from 0 to 100 , with a higher score indicating better health. The psychometric properties of the SF-12 were good: coefficients for testretest reliability, measured over two weeks, were 0.89 (PCS12) and 0.76 (MCS12) [34, 35]. Good internal consistency, validity, and responsiveness have been reported in patients with low back pain [36]. In the present study, the internal consistency was 0.89 (PCS12) and 0.86 (MCS12) at baseline.

\section{Statistical Analyses}

Factor analysis was conducted using exploratory maximum likelihood factor analysis and confirmatory factor analysis to validate the new RTWSE Scale at 1-month follow-up and 6-month follow-up. The sample at 1-month follow-up ( $n=632)$ and 6-month follow-up $(n=446)$ was randomly divided into two equal subsamples to allow for the crossvalidation of a first subsample using exploratory factor analysis with a second and different subsample that used confirmatory factor analysis. Exploratory maximum likelihood factor analysis was conducted, with orthogonal and oblique rotations, on the items from the first subsample at 1-month follow-up $(n=331)$ and 6-month follow-up $(n=220)$ in order to determine the underlying factor structure. Both rotations, Varimax (orthogonal) and Promax (oblique), were used because the correlations between emerging factors were initially unknown. If the pattern of correlation is similar using these two types of rotation, the solution from the exploratory factor analyses with Varimax rotation is then retained as this method tends to spread the variance equally between factors [41]. In determining the number of factors, Scree test criteria and explained variance were used. Items with loadings of .40 or higher were retained. Confirmatory factor analysis (CFA) was performed with the second subsample at 1-month follow-up $(n=331)$ and at 6-month follow-up $(n=220)$ to test the factor solution stemming from the first exploratory factor 
analysis. Using SAS 9.1 software [42] for the CFA, the Maximum Likelihood Estimation method was utilized to fit the model. Multiple indices such as the Chi-square/degrees of freedom ratio $\left(\chi^{2} / d f\right)$, the "Bentler and Bonnett's Non-normed Index" (NNFI), the "Bentler's Comparative Fit Index" (CFI), the "Bollen Non-normed Index Delta2" (IFI), as well as the "Root Mean Standard Error of Approximation" (RMSEA) were used to assess the fit of the models. Regarding the cut-off criteria of these indices, a $\chi^{2} / d f$ ratio of less than 5 [43], NNFI, CFI, and IFI higher than .90, and RMSEA less than .08 [44] were taken to indicate a good fit for the model $[45,46]$. Internal validity (Cronbach's alpha) for each of the dimensions extracted from the CFA was examined.

Construct validity was examined in several ways. First, we examined Pearson correlations between RTWSE Subscales and the theoretically relevant constructs. Second, $t$-tests were used to make multiple comparisons of RTWSE levels between groups based on work status (working/not working) and with low versus high levels of health-related outcomes, supervisor support, and self-reported duration of work disability, as based on the median split. Third, ANOVA tests were conducted to compare RTWSE levels between the four mutually exclusive RTW status groups. Fourth, participants were grouped into one of five Readiness stage-based groups based on their highest scores on the factorially derived readiness dimensions of Contemplation, Prepared-for-Action Behavioral, Prepared-for-Action Selfevaluative, Uncertain Maintenance, and Proactive Maintenance. Given that only five individuals had their highest score on the Precontemplation dimension, we excluded these individuals from any readiness group created. Participants with a tie between two subscales for the highest score were then placed in the least advanced group. Participants were excluded from the stage allocation approach if their highest score was equivalent on three subscales. This approach has been described elsewhere, while they were used in the validation study for the RRTW Scale [12]. Twosided ANOVA tests were conducted to compare RTWSE levels between the five Readiness stage-based groups. Since the direction of hypothesized changes is specified in the hypotheses the significance level for all other statistical tests, correlations and $t$-tests, was set at 0.05 one-sided.

\section{Results}

Participation Rates, Timing of Interviews, and Description of the Sample

A total of 632 claimants completed the baseline telephone interview 1 month post-injury with a participation rate of $61 \%$, consistent with participation rates of other cohort studies of adults with MSK conditions which range between 55\% [47] and 63\% [48]. A detailed description of the flow of participants is found elsewhere [30, 49]. A total of 446 participants completed the 6-month interview with a retention rate of $71 \%$. Average time between injury date and the baseline interview date was 29.6 days $(\mathrm{SD}=6.2$; range 15-46 days). For the 6-month interview, the average time between injury date and interview date was 178 days ( $\mathrm{SD}=11.1$; range 157-215 days). The socio-demographic characteristics of the sample at 1-month follow-up and 6-month follow-up are presented in Table 1.

\section{Selection and Attrition Bias Analyses}

Selection bias analyses conducted with WSIB data, described elsewhere [30], revealed that baseline participants and non-participants were generally comparable as to firm size, industrial sector, and income. However, participants were more likely to be older and female, and participants with accepted claims were more likely to be receiving wage replacement benefits for a longer duration and to have a higher rate of re-instatement of wage replacement benefits 6 months post-injury than non-participants, but not at 1 month post-injury, suggesting that the participants had longer work absences.

An attrition bias analysis, comparing respondents ( $n=446)$ to non-respondents (i.e., lost to follow-up) ( $n=186)$ of the 6-month interview, revealed that nonrespondents were more likely to have worked longer hours at time of injury, and to have specified "back" as their primary pain site [30]. Moreover, male non-respondents tended to be younger than male respondents, whereas in women, differences in age were not as apparent. Otherwise, non-respondents did not differ significantly from respondents with respect to other variables.

\section{Consent for Data Linkage Analysis}

Previous analyses reported elsewhere [50] showed no significant differences between baseline participants consenting to linkage of self-report data with administrative data, and those not providing consent, with respect to general workplace, health status, and work absence variables. However, nonconsenters had a lower level of education than consenters. No gender differences were detected, but a significant age $\times$ sex interaction was present, with young males being underrepresented in consenters.

\section{Exploratory and Confirmatory Factor Analyses}

The principal components analyses with Varimax and Promax rotations were conducted on the first subsample at 
Table 1 Socio-demographic characteristics for 632 workers at 1-month post-injury and for 446 workers at 6-month interview

\begin{tabular}{|c|c|c|c|c|}
\hline \multirow[b]{3}{*}{ Interview data } & \multicolumn{2}{|c|}{ One-month follow-up } & \multicolumn{2}{|c|}{ Six-month follow-up } \\
\hline & \multicolumn{2}{|c|}{$N=632$} & \multicolumn{2}{|c|}{$N=446$} \\
\hline & $N$ & $\%$ & $N$ & $\%$ \\
\hline Gender (male) & 350 & 55.4 & 238 & 53.4 \\
\hline Age categories & & & $(N=$ & \\
\hline $15-29$ years & 93 & 14.7 & 56 & 12.6 \\
\hline 30-39 years & 137 & 21.7 & 78 & 17.6 \\
\hline 40-49 years & 228 & 36.1 & 167 & 37.8 \\
\hline$\geq 50$ years & 173 & 27.4 & 144 & 32.0 \\
\hline \multicolumn{5}{|l|}{ Education } \\
\hline Some high school & 112 & 17.7 & 71 & 15.9 \\
\hline High school completed & 177 & 28.0 & 122 & 27.4 \\
\hline Some post-secondary & 130 & 20.6 & 92 & 20.6 \\
\hline Post-secondary/some graduate education & 213 & 33.7 & 161 & 36.1 \\
\hline Personal income & $(N=$ & & $(N=$ & \\
\hline$<\$ 20,000$ & 95 & 15.9 & 69 & 16.3 \\
\hline$\$ 20,000-39,999$ & 240 & 40.3 & 170 & 40.2 \\
\hline$\$ 40,000-59,999$ & 180 & 30.2 & 121 & 28.6 \\
\hline$>\$ 60,000$ & 81 & 13.6 & 63 & 14.9 \\
\hline \multicolumn{5}{|l|}{ Pain site } \\
\hline Back & 418 & 66.1 & 283 & 63.5 \\
\hline Upper extremities & 214 & 33.9 & 163 & 36.5 \\
\hline \multicolumn{5}{|l|}{ Number of hours worked at time of injury ${ }^{b}$} \\
\hline$\leq 37.5 \mathrm{~h} /$ Week & 179 & 28.3 & 142 & 31.8 \\
\hline 37.5-40 h/Week & 281 & 44.5 & 192 & 43.1 \\
\hline$\geq 40 \mathrm{~h} /$ Week & 172 & 27.2 & 112 & 25.1 \\
\hline $\begin{array}{l}\text { Number of workers at worksite } \\
\text { at time of injury }\end{array}$ & $(N=$ & & $(N=$ & \\
\hline$<20$ workers & 180 & 28.6 & 118 & 26.5 \\
\hline 20-99 workers & 199 & 31.6 & 143 & 32.1 \\
\hline 100-299 workers & 133 & 21.1 & 102 & 22.9 \\
\hline$\geq 300$ workers & 118 & 18.7 & 82 & 18.4 \\
\hline $\begin{array}{l}\text { Self-reported work absence: number } \\
\text { of work days missed at 1-month } \\
\text { interview (std) (median) }\end{array}$ & \multicolumn{2}{|c|}{$14.5(7.1)(14)$} & \multicolumn{2}{|c|}{$14.3(6.7)(14.0)$} \\
\hline $\begin{array}{l}\text { Self-reported work absence: number } \\
\text { of work days missed at 6-month } \\
\text { interview (std) (median) }\end{array}$ & & & 46.5 & \\
\hline \multicolumn{5}{|l|}{ WSIB data } \\
\hline Occupational classification & \multicolumn{2}{|c|}{$(N=536)^{\mathrm{c}}$} & \multicolumn{2}{|c|}{$(N=389)^{\mathrm{c}}$} \\
\hline White collar & 109 & 20.3 & 85 & 21.9 \\
\hline Pink collar & 209 & 39.1 & 154 & 39.6 \\
\hline Blue collar-indoor & 132 & 24.6 & 89 & 22.9 \\
\hline Blue collar-outdoor & 86 & 16.0 & 61 & 15.7 \\
\hline \multicolumn{5}{|l|}{ Firm size } \\
\hline$<20$ workers & 58 & 9.2 & 40 & 9.0 \\
\hline 20-99 workers & 100 & 15.8 & 67 & 15.0 \\
\hline 100-999 workers & 190 & 30.1 & 140 & 31.4 \\
\hline$\geq 1,000$ workers & 150 & 23.7 & 96 & 21.5 \\
\hline Schedule $2^{\mathrm{d}}$ & 134 & 21.2 & 103 & 23.1 \\
\hline
\end{tabular}


Table 2 Exploratory factor structure of the RTWSE Scale at 1-month and 6-month follow-ups-loadings of each item on each of the three factors

\begin{tabular}{|c|c|c|c|c|c|c|}
\hline \multirow[t]{3}{*}{ Items } & \multicolumn{3}{|c|}{ One-month follow-up $(N=316)$} & \multicolumn{3}{|c|}{ Six-month follow-up $(N=220)$} \\
\hline & \multicolumn{3}{|l|}{ Subscale } & \multicolumn{3}{|l|}{ Subscale } \\
\hline & $\begin{array}{l}\text { Supervisor } \\
\text { RTWSE }\end{array}$ & $\begin{array}{l}\text { Pain } \\
\text { RTWSE }\end{array}$ & $\begin{array}{l}\text { Co-workers } \\
\text { RTWSE }\end{array}$ & $\begin{array}{l}\text { Supervisor } \\
\text { RTWSE }\end{array}$ & $\begin{array}{l}\text { Pain } \\
\text { RTWSE }\end{array}$ & $\begin{array}{l}\text { Co-workers } \\
\text { RTWSE }\end{array}$ \\
\hline $\begin{array}{l}\text { Will be able to talk to supervisor if problems } \\
\text { occur during RTW }\end{array}$ & 0.825 & 0.130 & 0.250 & 0.842 & 0.243 & 0.035 \\
\hline $\begin{array}{l}\text { Can discuss with supervisor about things that } \\
\text { contribute to pain }\end{array}$ & 0.891 & 0.129 & 0.201 & 0.926 & 0.088 & 0.248 \\
\hline Explain physical limitations to supervisor & 0.870 & 0.102 & 0.188 & 0.902 & 0.094 & 0.260 \\
\hline Suggest way to reduce discomfort to supervisor & 0.704 & 0.190 & 0.286 & 0.793 & 0.134 & 0.250 \\
\hline Will be able to remain once back at work & 0.025 & 0.741 & -0.109 & 0.242 & 0.668 & 0.117 \\
\hline Can continue working despite pain & 0.018 & 0.823 & 0.166 & 0.050 & $\mathbf{0 . 8 3 0}$ & 0.049 \\
\hline Can avoid re-injury & 0.158 & 0.657 & 0.064 & 0.090 & 0.786 & 0.081 \\
\hline Can manage pain effectively while you work & 0.068 & 0.760 & 0.294 & 0.115 & 0.857 & 0.126 \\
\hline Can get co-workers to help you & 0.154 & 0.238 & 0.805 & 0.180 & 0.235 & 0.876 \\
\hline Explain physical limitations to co-workers & 0.276 & 0.023 & 0.779 & 0.373 & 0.052 & 0.836 \\
\hline Variance after rotation $(\%)$ & 29.20 & 23.73 & 15.44 & 32.62 & 26.39 & 16.98 \\
\hline
\end{tabular}

Internal Validity

Cronbach's alphas were satisfactory at 1-month follow-up (0.88 for Supervisor RTWSE, 0.76 for Pain RTWSE, and 0.66 for Co-workers RTWSE) and T2 (0.93 for Supervisor RTWSE, 0.76 for Pain RTWSE, and 0.79 for Co-workers RTWSE).

\section{Construct Validity of Subscales}

No significant correlations between the three RTWSE Subscales and socio-demographic characteristics-age, education, and annual personal income-were found.

To test the hypotheses related to the construct validity of the scale, we used both correlations and differences between the subscales of the RTWSE Scale and other constructs described above. Due to the finding of three RTWSE Subscales, some of the hypotheses were refined to address in more detail the hypothesized association between each of the subscales and the other constructs as follows: (1) All subscales will be strongly related to readiness levels (Primary Hypothesis 1) and RTW status (Primary Hypothesis 2); (2) Supervisor RTWSE will be strongly related to supervisor interaction (Primary Hypothesis 3); and (3) Pain RTWSE will be strongly related to current pain, depression, health status (Secondary Hypotheses 1 and 2). The results concerning these more specific hypotheses are described below. An overview of all results is given in Tables 3 and 4 (ANOVA analyses for Readiness for RTW stages and for RTW status, respectively), Table 5 (correlations), and Tables 6 and 7 ( $t$-tests at 1 - and 6-month follow-ups).

Primary Hypothesis 1 Low self-efficacy will be associated with less advanced stages of change.

ANOVA tests were conducted to compare scores on the Self-efficacy Subscale as the dependent variable with five subgroups of workers based on the stages of change for each of the three subscales at 1- and 6-month follow-ups (see Table 3). All univariate $F$-tests were significant at 1- and 6-month follow-ups, except for the Co-workers Selfefficacy Subscale at 1-month follow-up. At both 1-month and 6-month follow-ups, the mean scores of the three subscales of self-efficacy increased over time in more advanced stages of change; it decreased, however, when comparing the mean scores of the Prepared-for-Action Behavioral phase and the Uncertain Maintenance phase on all three subscales of Self-efficacy for RTW Scale at both measurement times.

Primary Hypothesis 2 Low self-efficacy will be associated with less optimal RTW status.

ANOVA tests were conducted to compare scores on the Self-efficacy Subscale scores as the dependent variable, with three subgroups of workers based on the RTW status as the independent variable: (1) sustained first return to work (RTW-S), (2) return to work with recurrence(s) of work absence (RTW-recurrences), and (3) no return to work (No RTW) at 1-month and 6-month follow-ups (see Table 4). Significant differences were found only for the 


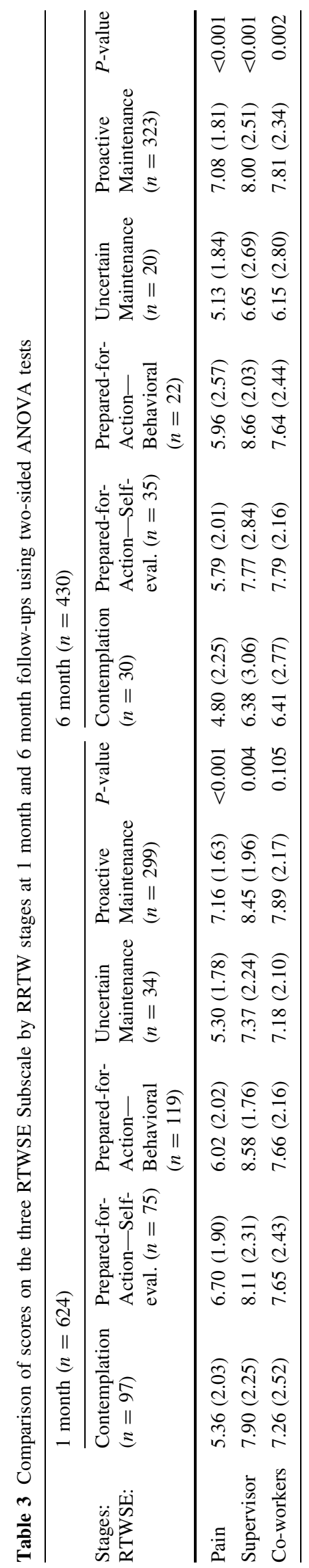

Pain Self-efficacy for RTW Subscale, both at 1-month and 6-month follow-ups. With regard to the self-reported duration of work disability, significant negative correlations were only found on the Pain RTWSE Subscale at 1-month and 6-month follow-ups. T-tests revealed that workers with longer duration of work disability reported significantly lower levels of Pain RTWSE only at 1-month follow-up.

Primary Hypothesis 3 Low self-efficacy will be associated with less perceived social support from supervisor and co-workers.

Significant correlations were found between the Supervisor interaction scale and the Supervisor RTWSE Subscale at 1-month and 6-month follow-ups (see Table 5). $T$-tests revealed that workers with high levels of supervisor interaction reported significantly higher levels of Supervisor RTWSE at 1-month and 6-month follow-ups (see Tables 6 and 7).

Primary Hypothesis 4 The strength of the relationships between the theoretical constructs and the RTWSE subscales will be stronger 6 months post Injury as compared to 1 month.

In general, higher significant correlations were found for the three RTWSE Subscales at 6-month follow-up on all constructs compared to 1-month follow-up data (see Table 5).

Secondary Hypothesis 1 Low self-efficacy will be associated with more impaired levels of physical health, mental health (including depressive symptoms), and functional ability.

The significant correlations were between physical health and mental health, and the Pain RTWSE Subscale at 1-month and 6-month follow-ups (see Table 5). T-tests revealed that workers with higher levels of health status reported significantly higher levels of Pain RTWSE both at T1 and T2 (see Tables 6 and 7).

Significant negative correlations were found between Depression and the Pain RTWSE Subscale at 1-month and 6-month follow-ups (see Table 5). T-tests also revealed that workers with high levels of depression reported significantly lower levels of Pain Self-efficacy at both follow-up measurements (see Tables 6 and 7).

Secondary Hypothesis 2 Low self-efficacy will be associated with higher levels of pain.

Significant correlations were found between current pain and the Pain RTWSE Subscale at 1-month and 6-month follow-ups (see Table 5). T-tests revealed that workers with high levels of current pain reported significantly lower levels of self-efficacy (see Tables 6 and 7). 
Table 4 Comparison of scores on the RTWSE Subscale by RTW status groups at 1 month and 6 month follow-ups using two-sided ANOVA tests

\begin{tabular}{|c|c|c|c|c|c|c|c|c|}
\hline \multirow[b]{2}{*}{$\begin{array}{l}\text { RTW status: } \\
\text { RTWSE: }\end{array}$} & \multicolumn{4}{|l|}{1 month } & \multicolumn{4}{|l|}{6 months } \\
\hline & $\begin{array}{l}\text { RTW } \\
(n=333)\end{array}$ & $\begin{array}{l}\text { RTW-recurrences } \\
(n=55)\end{array}$ & $\begin{array}{l}\text { No RTW } \\
(n=244)\end{array}$ & $P$-value & $\begin{array}{l}\text { RTW } \\
(n=332)\end{array}$ & $\begin{array}{l}\text { RTW-recurrences } \\
(n=72)\end{array}$ & $\begin{array}{l}\text { No RTW } \\
(n=39)\end{array}$ & $P$-value \\
\hline Pain & 6.97 (1.74) & $5.92(2.08)$ & $5.92(2.08)$ & $<0.001$ & 6.99 (1.89) & $5.97(2.21)$ & $5.05(2.26)$ & $<0.001$ \\
\hline Supervisor & $8.34(2.02)$ & 8.08 (1.93) & $8.20(2.20)$ & 0.572 & $7.84(2.44)$ & 7.47 (2.68) & $7.86(2.78)$ & 0.520 \\
\hline Co-workers & $7.82(2.17)$ & $7.65(2.22)$ & $7.45(2.42)$ & 0.160 & $7.69(2.42)$ & $7.42(2.33)$ & $7.28(2.67)$ & 0.482 \\
\hline
\end{tabular}

Table 5 Correlations between RTWSE Subscales and relevant constructs at 1 month $(N=632)$ and 6 month follow-up $(N=442)$

\begin{tabular}{|c|c|c|c|c|c|c|}
\hline \multirow{2}{*}{$\begin{array}{l}\text { Subscales } \\
\text { Measurement }\end{array}$} & \multicolumn{2}{|c|}{ Pain RTWSE } & \multicolumn{2}{|c|}{ Supervisor RTWSE } & \multicolumn{2}{|c|}{ Co-workers RTWSE } \\
\hline & 1 month & 6 months & 1 month & 6 months & 1 month & 6 months \\
\hline Current pain & $-0.32 * *$ & $-0.38 * *$ & -0.07 & $-0.10 *$ & $-0.15^{* *}$ & $-0.22 * *$ \\
\hline Depression & $-0.31 * *$ & $-0.39 * *$ & $-0.23 * *$ & $-0.26^{* *}$ & $-0.14 * *$ & $-0.22 * *$ \\
\hline SF-12 physical & $0.22 *$ & $0.41 * *$ & -0.03 & 0.09 & 0.04 & $0.18 *$ \\
\hline SF-12 mental & $0.22 *$ & $0.33 * *$ & $0.13 * *$ & $0.28 * *$ & 0.08 & $0.21 * *$ \\
\hline Ready to go back to work & $0.42 * *$ & $0.51 * *$ & $0.11 * *$ & $0.17 * *$ & $0.09 *$ & $0.28 * *$ \\
\hline Supervisor interaction & $0.17 * *$ & $0.29 * *$ & $0.45^{* *}$ & $0.59 * *$ & $0.31 * *$ & $0.33 * *$ \\
\hline Duration of work disability (self-report) & $-0.18 * *$ & $-0.23 * *$ & 0.03 & 0.07 & -0.02 & -0.01 \\
\hline
\end{tabular}

$* P \leq 0.05 ; * * P \leq 0.01$ (one-sided)

Table 6 Comparisons between theoretically relevant constructs and the three RTWSE Subscales at 1-month follow-up using one-sided $T$-test

\begin{tabular}{|c|c|c|c|c|c|c|c|c|c|c|c|}
\hline \multirow{2}{*}{$\begin{array}{l}\text { Subscales } \\
\text { Measurement (median) }\end{array}$} & \multirow[t]{2}{*}{$D f=630$} & \multirow[t]{2}{*}{$N$} & \multicolumn{3}{|l|}{ Pain SE } & \multicolumn{3}{|c|}{ Supervisor SE } & \multicolumn{3}{|c|}{ Co-workers SE } \\
\hline & & & Mean (sd) & $T$ value & $P$-value & Mean (sd) & $T$ value & $P$-value & Mean (sd) & $T$ value & $P$-value \\
\hline \multirow[t]{2}{*}{ Current pain (5.00) } & Low & 356 & $6.97(1.81)$ & 7.53 & $<0.001$ & 8.44 (1.98) & 2.36 & 0.001 & $7.92(2.16)$ & 3.30 & 0.006 \\
\hline & High & 276 & $5.82(2.00)$ & & & $8.04(2.19)$ & & & $7.32(2.39)$ & & \\
\hline \multirow[t]{2}{*}{ Depressive symptoms (14.00) } & Low & 321 & $6.98(1.80)$ & -6.64 & $<0.001$ & $8.62(1.88)$ & -4.23 & $<0.001$ & $7.93(2.22)$ & -2.91 & 0.002 \\
\hline & High & 311 & $5.97(2.01)$ & & & $7.93(2.21)$ & & & $7.40(2.34)$ & & \\
\hline \multirow[t]{2}{*}{ SF-12 physical (34.02) } & Low & 318 & $6.16(1.98)$ & 3.92 & $<0.001$ & $8.27(2.15)$ & -0.03 & 0.490 & $7.61(2.31)$ & 0.60 & 0.275 \\
\hline & High & 314 & $6.77(1.93)$ & & & $8.26(2.02)$ & & & $7.71(2.25)$ & & \\
\hline \multirow[t]{2}{*}{ SF-12 mental (47.54) } & Low & 316 & $6.00(2.01)$ & 6.20 & $<0.001$ & $7.95(2.22)$ & 3.81 & $<0.001$ & $7.41(2.35)$ & 2.75 & 0.003 \\
\hline & High & 316 & $6.95(1.82)$ & & & $8.58(1.89)$ & & & $7.91(2.18)$ & & \\
\hline \multirow{2}{*}{$\begin{array}{l}\text { Ready to go back to } \\
\text { work }(6.00)\end{array}$} & Low & 283 & $5.71(1.98)$ & 9.30 & $<0.001$ & $8.00(2.25)$ & 2.92 & 0.002 & $7.38(2.33)$ & 2.78 & 0.003 \\
\hline & High & 349 & 7.09 (1.75) & & & $8.48(1.91)$ & & & $7.89(2.22)$ & & \\
\hline \multirow[t]{2}{*}{ Supervisor interaction (27.00) } & Low & 280 & 6.15 (1.97) & 3.62 & $<0.001$ & $7.41(2.33)$ & 10.15 & $<0.001$ & $6.93(2.34)$ & 7.65 & $<0.001$ \\
\hline & High & 344 & $6.72(1.95)$ & & & $8.98(1.50)$ & & & $8.27(2.04)$ & & \\
\hline \multirow{2}{*}{$\begin{array}{l}\text { Duration of work disability } \\
\text { (self-report) (14.5) }\end{array}$} & Low & 321 & $6.84(1.82)$ & -4.89 & $<0.001$ & $8.18(2.14)$ & 1.05 & 0.145 & $7.68(2.22)$ & -0.25 & 0.401 \\
\hline & High & 311 & $6.09(2.06)$ & & & $8.36(2.02)$ & & & $7.64(2.34)$ & & \\
\hline
\end{tabular}

\section{Discussion}

Our primary objective was to develop a theoretically based and validated scale to measure self-efficacy within the context of the process of return-to-work. We developed a 10-item questionnaire with three factorially derived subscales: Supervisor RTWSE, Pain RTWSE, and Co-workers RTWSE. Our findings support the internal validity of a 
Table 7 Comparison between theoretically relevant constructs and the three RTWSE Subscales at 6-month follow-up using one-sided $T$-test

\begin{tabular}{|c|c|c|c|c|c|c|c|c|c|c|c|c|c|}
\hline \multirow{2}{*}{$\begin{array}{l}\text { Subscales } \\
\text { Measurement (median) }\end{array}$} & & \multirow[t]{2}{*}{$N$} & \multicolumn{3}{|l|}{ Pain SE } & \multicolumn{4}{|c|}{ Supervisor SE } & \multicolumn{4}{|c|}{ Co-workers SE } \\
\hline & & & Mean (sd) & $T$ value & $P$-value & $N$ & Mean (sd) & $T$ value & $P$-value & $N$ & Mean (sd) & $T$ value & $P$-value \\
\hline \multirow[t]{2}{*}{ Current pain (3.00) } & Low & 221 & $7.34(1.76)$ & -4.45 & $<0.001$ & 220 & $8.11(2.24)$ & -2.76 & 0.003 & 219 & $8.11(2.20)$ & -4.336 & $<0.001$ \\
\hline & High & 222 & $5.96(2.12)$ & & & 220 & $7.46(2.71)$ & & & 220 & $7.12(2.55)$ & & \\
\hline \multirow[t]{2}{*}{ Depression (6.00) } & Low & 206 & $7.43(1.75)$ & -8.00 & $<0.001$ & 205 & $8.38(2.19)$ & -4.79 & $<0.001$ & 204 & $8.11(2.30)$ & -4.07 & $<0.001$ \\
\hline & High & 236 & $5.96(2.08)$ & & & 234 & $7.18(2.47)$ & & & 234 & $7.18(2.47)$ & & \\
\hline \multirow[t]{2}{*}{ SF-12 physical (43.34) } & Low & 221 & $5.82(2.10)$ & 9.24 & $<0.001$ & 218 & $7.40(2.62)$ & 3.23 & $<0.001$ & 217 & $7.19(2.54)$ & 3.66 & $<0.001$ \\
\hline & High & 222 & 7.48 (1.66) & & & 222 & $8.16(2.33)$ & & & 222 & $8.03(2.25)$ & & \\
\hline \multirow[t]{2}{*}{ SF-12 mental (53.19) } & Low & 221 & $6.06(2.02)$ & 6.26 & $<0.001$ & 219 & $7.26(2.63)$ & 4.50 & $<0.001$ & 219 & $7.13(2.47)$ & 4.27 & $<0.001$ \\
\hline & High & 222 & 7.24 (1.94) & & & 221 & $8.31(2.27)$ & & & 220 & $8.10(2.29)$ & & \\
\hline \multirow{2}{*}{$\begin{array}{l}\text { Ready to go back } \\
\text { to work }(8.00)\end{array}$} & Low & 176 & $5.46(2.00)$ & 11.18 & $<0.001$ & 174 & $7.21(2.72)$ & 3.95 & $<0.001$ & 174 & $6.77(2.59)$ & 6.17 & $<0.001$ \\
\hline & High & 267 & $7.44(1.70)$ & & & 266 & $8.16(2.29)$ & & & 265 & $8.17(2.15)$ & & \\
\hline \multirow{2}{*}{$\begin{array}{l}\text { Supervisor interaction } \\
\quad(27.00)\end{array}$} & Low & 211 & $6.09(2.12)$ & 5.68 & $<0.001$ & 210 & $6.47(2.74)$ & 12.38 & $<0.001$ & 210 & $6.77(2.53)$ & 7.57 & $<0.001$ \\
\hline & High & 222 & $7.19(1.90)$ & & & 221 & $9.04(1.40)$ & & & 220 & $8.43(2.00)$ & & \\
\hline \multirow{2}{*}{$\begin{array}{l}\text { Duration of work } \\
\text { disability (self-report) } \\
(20.00)\end{array}$} & Low & 219 & $6.86(1.96)$ & -2.09 & 0.219 & 218 & $7.64(2.48)$ & 1.21 & 0.114 & 218 & $7.72(2.32)$ & -0.88 & 0.190 \\
\hline & High & 224 & $6.45(2.15)$ & & & 223 & $7.93(2.53)$ & & & 223 & $7.51(2.53)$ & & \\
\hline
\end{tabular}

RTWSE Scale as applied to a sample of injured workers with work-related MSK disorders who had made a losttime claim. Exploratory and confirmatory factor analyses confirmed the presence of the a priori hypothesized factors-(1) Obtain help from supervisor, (2) Manage and cope with pain and (3) Obtain help from co-workerswhich corresponds closely to the factors described by Shaw and Huang [1]. All items were below the saturation level of 0.40 . The amount of variance explained by the factor analysis was significant $(>50 \%)$, alpha coefficients were equal to or superior to .66, and correlations between factor subscales were low to moderate (between 0.33 and 0.52 ), which is common in psychological research. The fit indices were satisfactory at T1 and T2, except for the RMSEA. We would be most confident in the factor structure if all fit indices had met our specified criteria. However, note that all other fit indices were more than adequate, the exploratory factor structure was consistent at both time points, the factor structure was clean and sensible with no complex loadings, and the Cronbach's alpha were satisfactory.

Our secondary objectives included the establishment of the subscales' construct validity by examining whether they related to other relevant constructs in the theoretically expected way. The hypothesized theoretically-based expected relationships between current pain, depression, health status and supervisor interaction, and the SE for RTW Subscales were generally in the expected direction for the pain RTWSE subscale, while results pertaining to the coworker and supervisor RTWSE items showed some inconsistency in their relationships with other constructs. The hypothesis that less advanced stages of change on the
RRTW Scale would be associated with lower RTWSE on all subscales could not be completely confirmed. While workers in the less advanced stage of Contemplation reported lower levels of RTWSE than workers in the more advanced stages of Prepared-for-Action (Self-evaluation and Behavioral), and of Proactive Maintenance, RTWSE scores were significantly lower for workers in the Uncertain Maintenance stage as opposed to those in the Preparedfor-Action Behavioral stage for all RTWSE Subscales at both time points. Our findings are significant and meaningful, because they indicate that RTWSE is at its peak in workers who are actively preparing to return to work, and because they show that RTWSE decreases significantly for some people who start working again, and experience discouragement and uncertainty about the likelihood of being able to remain back at work as in the Uncertain Maintenance stage. By contrast, for workers in the Proactive Maintenance phase, the phase in which workers report proactive and positive strategies to remain at work such as the use of specific skills and social support to identify and face high-risk situations for relapse, RTWSE remains high.

While clear and generally expected relationships were observed between RTWSE and RRTW stages, the relationships with RTW status and work disability duration were less clear. Indeed, only the Pain RTWSE showed significant relationships with RTW status and duration of work disability as predicted. Only those workers with sustained first return to work and those with shorter duration of work disability showed the highest Pain RTWSE scores. Taken together, our findings suggest that one possible explanation for the weak association between RTWSE and 
work status/work disability duration and the stronger association between RTWSE and RRTW stages may lie in the difference between the intention/motivation for the behavior and the actual behavior [51]. While the RRTW stages capture both internalized processes (intention and motivation) and actual behavior, work status and work absence reflect solely the actual behavior. Our findings suggest that selfefficacy is more strongly associated with internalized processes of behavior than strictly behavioral ones.

With regard to the change over time, the strength of association between self-efficacy and other theoretically derived constructs was stronger at 6 months post-injury compared to 1 month post-injury, suggesting that the associations between these psychological constructs consolidate over time after the disruptive event of the injury. The relationships between self-efficacy and other constructs being different at 1 and 6 months may be impacted by the fact that there are slightly different samples of people used at the two time points. To that end, we have repeated the analyses (correlations, $t$-test and Anova-test) using the sample of subjects who have data available at both time points $(n=430)$ and find no relevant differences between the results except with respect to the association between the Co-Worker RTWSE scale and the RRTW stages which became significant in our second analysis ( $P=0.007$ vs. 0.105 ) (hypothesis 1$)$. Therefore, we decided to present the data of all 632 subjects at 1-month follow-up instead of the subsample of 430 participants. It should be noted that studies which explore instruments' construct validity by studying measured qualities at different time frames are scarce.

The single strongest correlation was found between Supervisor Interaction and Supervisor RTWSE. However, for all other theoretically derived constructs, stronger correlations were found for Pain RTWSE. Compared to the other two types of self-efficacy, Supervisor and Co-workers RTWSE, the highest correlations were found between Pain RTWSE, and current pain, depression, health status, work status and duration of work disability. This suggests that experience with pain, including self-efficacy about ability to cope with pain, may be a stronger determining factor in the RTW trajectory process, as indexed by duration of absence, than self-efficacy about supervisor and co-workers alone. The absence of significant findings regarding supervisor and co-workers self-efficacy stand in contrast to those of previous studies where supervisor and co-workers behaviors were found to be determinants of return to work [10, 52, 53].

The importance of Pain RTWSE is corroborated by previous research which stresses the importance of positive Pain RTWSE for successful adaptation to chronic pain [54-56]. A lower Pain RTWSE level was associated with a higher level of pain intensity, and depression and health status correlated. Lower self-efficacy, or the lack of belief in one's own ability to manage pain, to cope and function despite persistent pain, has been found to be a significant predictor of the extent to which individuals with chronic pain become disabled and/or depressed [54, 57]. These findings point to the importance of incorporating strategies in RTW interventions to enhance self-efficacy beliefs, that is, strategies to prevent reinjury and pain exacerbation, and to manage and tolerate pain through self-management.

Supervisor RTWSE and Co-workers RTWSE were highly associated with supervisor interaction after injury. Supervisor RTWSE reflects the degree to which workers are certain of their ability to discuss openly with their supervisor those issues that may contribute to pain problems, and to explain any physical limitations and ways to change their work so as to reduce discomfort. Social support from supervisors is one of the key dimensions that contribute to job stress according to Johnson's extension of Karasek's job demand-control model of job stress [58]. Supervisors play a key role in the return-to-work process, and are most familiar with the requirements of the job, they are the first to communicate with workers about return to work, and they usually have the authority to implement adjustments in working conditions [59].

In terms of limitations of the study, a questionnaire about co-workers interaction was not used in our study, therefore we could only compare the results of the Co-workers RTWSE Subscale with other theoretical constructs. In addition, some domains of self-efficacy were not addressed by the scale. Indeed, with regard to the subdomain "obtaining help from others," Shaw and Huang [1] reported items related to accommodation, which was not addressed by our scale. In addition, a third sub-domain about job demands was reported in their study with regard to Self-efficacy for RTW, which consisted of items about quantity, role, speed, and quality of someone's work performance, and which is not addressed by our scale.

One strength of our study is the use of exploratory and confirmatory factor analyses with two separate samples, which lends strong support to the validity of our factor analytic findings. In addition, the fact that all retained items loading on the three factors at T1 and T2 (except for the RMSEA) suggest that our scale is consistent over time, which is an important requirement in longitudinal research and reflects solid internal validity for the construct. A methodological strength is that comprehensive selection and consent bias analyses show that there does not appear to be any systematic biases present in our analyses. However, the generalizability of our study results remains limited with regard to injured workers with shorter duration of receiving wage replacement benefits and to younger males.

The development and validation of a measurement of RTWSE is an important step in the application of the 
RRTW model within the RTW process. A next step in the validation process of the RTWSE Scale would be to consider longitudinally the predictive validity of the instrument. In addition, the validity of the measurement should be evaluated with workers presenting with physical and mental conditions other than MSK disorders. Finally, the validity of the RTWSE Scale needs to be explored within the context of intervention research for RTW. This new measurement of RTWSE can assist in evaluating the effectiveness of RTW interventions.

Open Access This article is distributed under the terms of the Creative Commons Attribution Noncommercial License which permits any noncommercial use, distribution, and reproduction in any medium, provided the original author(s) and source are credited.

\section{References}

1. Shaw WS, Huang YH. Concerns and expectations about returning to work with low back pain: identifying themes from focus groups and semi-structured interviews. Disabil Rehabil. 2005;27(21): 1269-81.

2. Franche RL, Krause N. Readiness for return to work following injury and illness: conceptualizing the interpersonal impact of health care, workplace, and insurance factors. J Occup Rehabil. 2002;12:233-56.

3. Prochaska JO, Diclemente CC. Stages and processes of selfchange of smoking: toward an integrative model of change. J Consult Clin Psychol. 1983;51(3):390-5.

4. Krause N, Ragland DR. Occupational disability due to low back pain: a new interdisciplinary classification based on a phase model of disability. Spine. 1994;19:1011-20.

5. Frank J, Sinclair S, Hogg-Johnson S, Shannon H, Bombardier C, Beaton D, Cole D. Preventing disability from work-related lowback pain: new evidence gives new hope-If we can just get all the players on one side. CMAJ. 1998;158(12):1625-31.

6. Prochaska JO, Diclemente CC, Velicer WF, Ginpil S, Norcross JC. Predicting change in smoking status for self-changers. Addict Behav. 1985;10(4):395-406.

7. Prochaska JO, Diclemente CC, Norcross JC. In search of how people change. Applications to addictive behaviors. Am Psychol. 1992;47(9):1102-14.

8. Prochaska JO, Velicer WF, Diclemente CC, Fava J. Measuring processes of change: applications to the cessation of smoking. J Consult Clin Psychol. 1988;56(4):520-8.

9. Velicer WF, Norman GJ, Fava JL, Prochaska JO. Testing 40 predictions from the transtheoretical model. Addict Behav. 1999; 24(4):455-69.

10. Krause N, Dasinger LK, Deegan LJ, Rudolph L, Brand RJ. Psychosocial job factors and return-to-work after compensated low back injury: a disability phase-specific analysis. Am J Ind Med. 2001;40:374-92.

11. Shanfield SB. Return to work after an acute myocardial infarction: a review. Heart Lung J Crit Care. 1990;19(2):109-17.

12. Franche RL, Corbière M, Lee H, Breslin FC, Hepburn CG. The readiness for return-to-work (RRTW) scale: development and validation of a self-report staging scale in lost-time claimants with musculoskeletal disorders. J Occup Rehabil. 2007;17: 450-72.

13. Bandura A. Self-efficacy: toward a unifying theory of behavioral change. Psychol Rev. 1977;84:191-215.
14. Scherer M, Maddux JE, Mercandante B, Prentice-Dunn S, Jacobs B, Rogers RW. The self-efficacy scale: construction and validation. Psychol Rep. 1982;51:663-71.

15. Arnetz BB, Sjogren B, Rydehn B, Meisel R. Early workplace intervention for workers with musculoskeletal-related absenteeism: a prospective controlled intervention study. J Occup Environ Med. 2003;45:499-506.

16. Kosny A, Franche RL, Pole J, Krause N, Cote P, Mustard C. Early healthcare provider communication with patients and their workplace following a lost-time claim for an occupational musculoskeletal injury. J Occup Rehabil. 2006;16:27-39.

17. Labriola M, Lund T, Christensen KB, Albertsen K, Bültmann U, Jensen JN, Villadsen E. Does self-efficacy predict return-to-work after sickness absence? A prospective study among 930 workers with sickness absence for three weeks or more. Work. 2007;29: 233-8.

18. van Oostrom SH, Anema JR, Terluin B, de Vet HC, Knol DL, van Mechelen W. Cost-effectiveness of a workplace intervention for sick-listed workers with common mental disorders: design of a randomized controlled trial. BMC Public Health. 2008;14:8-12.

19. Labriola M, Lund T, Burr H. Prospective study of physical and psychosocial risk factors for sickness absence. Occup Med. 2006; $56: 469-74$

20. Fitzgerald S, Becker D, Celentano D, Swank R, Brinker J. Return to work after percutaneous transluminal coronary angioplasty. Am J Cardiol. 1989;68(18):1108-12.

21. Brouwer S, Krol B, Reneman MF, Bültmann U, Franche RL, van der Klink JJL, Groothoff JW. Behavioral determinants as predictors of return to work after long-term sickness absence: an application of the theory of planned behavior. J Occup Rehab. 2009; 19(2):166-74.

22. Lötters F, Franche RL, Hogg-Johnsons, Burdorf A, Pole JD. The prognostic value of depressive symptoms, fear-avoidance, and self-efficacy for duration of lost-time benefit in workers with musculoskeletal disorders. J Occup Environ Med. 2006;63(12): 794-801.

23. Dasinger LK. Physical workplace factors and return to work after compensated low back injury: a disability phase-specific analysis. J Occup Environ Med. 2000;42(3):323-33.

24. Krause N, Frank JW, Dasinger LK, Sullivan TJ, Sinclair SJ. Determinants of duration of disability and return-to-work after work-related injury and illness: challenges for future research. Am J Ind Med. 2001;40:464-84.

25. Streiner D, Norman G. Health measurement scales. A practical guide to their development and use. Cambridge: Oxford Medical Publications, Oxford University Press; 2002.

26. Shaw WL, Linton SJ, Pransky G. Reducing sickness absence from work due to low back pain: how well do intervention strategies match modifiable risk factors? J Occup Rehabil. 2006;16: 591-605.

27. Mierlo H, van Rutte CG, Vermunt JK, Kompier MAJ, Doorewaard JAMC. Individual autonomy in work teams: the role of team autonomy, self-efficacy, and social support. Eur J Work Org Psychol. 2006;15(3):281-99.

28. Keefe FJ, Lefebvre JC, Kerns RD, Rosenberg R, Beaupre P, Prochaska J, Prochaska JO, Caldwell DS. Understanding the adoption of arthritis self-management: stages of change profiles among arthritis patients. Pain. 2000;87:303-13.

29. Norman G, Fava JL, Levesque DA, Redding CA, Johnson S, Evers K, Reich T. An inventory for measuring confidence to manage stress. Ann Behav Med. 1997;19(Suppl):78.

30. Bültmann U, Franche RL, Hogg-Johnson S, Côté P, Lee H, Severin C, Vidmar M, Carnide N. Health status, work limitations, and return-to-work trajectories in injured workers with musculoskeletal disorders. Qual Life Res. 2007;16(7):1167-78. 
31. Lorig K, Chastain RL, Ung E, et al. Development and evaluation of a scale to measure perceived self-efficacy in people with arthritis. Arthritis Rheum. 1989;32:37-44.

32. Von Korff M, Jensen MP, Karoly P. Assessing global pain severity by self-report in clinical and health services research. Spine. 2000;25:3140-51.

33. Radloff LS. The CES-D scale: a self-report depression scale for research in the general population. Appl Psychol Measur. 1977;1: 385-401.

34. Ware J, Kosinski M, Keller SD. A 12-Item short-form health survey: construction of scales and preliminary tests of reliability and validity. Med Care. 1996;34:220-33.

35. Ware J, Kosinski M, Keller SD. SF-12: how to score the SF-12 physical and mental health summary scales. Lincoln: Quality Metric Inc; 2002.

36. Luo X, Lynn GM, Kakouras I, Edwards CL, Pietrobon R, Richardson W, Hey L. Reliability, validity, and responsiveness of the short form 12-item survey (SF-12) in patients with back pain. Spine. 2003;28:1739-45.

37. Pransky G, Benjamin K, Hill-Fotouhi C, Himmelstein J, Fletcher $\mathrm{KE}$, Katz JN, et al. Outcomes in work-related upper extremity and low back injuries: results of a retrospective study. Am J Ind Med. 2000;37:400-9.

38. Smith J, Tarsuk V, Ferrier S, Shannon H. Relationship between workers' reports of problems and legitimacy and vulnerability in the workplace a duration of benefits for lost-time musculoskeletal injuries. Am J Epidemiol. 1996;143(11):S17.

39. Kerns RD, Rosenberg R, Jamison RN, Caudill MA, Haythornthwaite J. Readiness to adopt a self-management approach to chronic pain: the pain stages of change questionnaire (PSOCQ). Pain. 1997;72:227-34.

40. Carr JL, Moffett JAK, Sharp DM, Haines DR. Is the pain stages of change questionnaire (PSOCQ) a useful tool for predicting participation in a self-management programme? Further evidence of validity, on a sample of UK pain clinic patients. BMC Musculoskelet Disord. 2006;7:1-7.

41. Tabachnick BG, Fidell LS, editors. Using multivariate statistics. 3rd ed. California: California State University. Northridge Harper Collins College Publishers; 1996.

42. SAS Statistical Software. 2004; version 9.1.

43. Bollen KA. Structural equations with latent variables. New York: Wiley; 1989.

44. Browne MW, Cudeck R. Alternative ways of assessing model fit. In: Testing structural equation models. Newbury Park, CA: Sage Publications, Inc; 1993. pp. 136-162.

45. Jõreskog KG, Sorbom D. LISREL 8: user's reference guide. Mooresville: Scientific Software; 1993.
46. Mueller RO. Basic principles of structural equation modeling: an introduction to LISREL and EQS. New York: Springer; 1996.

47. Cassidy JD, Côté P, Carroll LJ, Kristman V. Incidence and course of low back pain episodes in the general population. Spine. 2005; 30(24):2817-23.

48. Sinclair SJ, Hogg-Johnson SA, Mondloch MV, Shields SA. The effectiveness of an early active intervention program for workers with soft tissue injuries: the Early Claimant Cohort study. Spine. 1997;22(24):2919-31.

49. Franche R-L, Carnide N, Hogg-Johnson S, Côté P, Breslin CF, Bültmann U, Severin CN, Krause N. Course, diagnosis, and treatment of depressive symptomatology in workers following a workplace injury: a prospective study. Can J Psych. 2009;54: 534-46.

50. Franche R-L, Severin C, Hogg-Johnson S, Côté P, Vidmar M, Lee $\mathrm{H}$. The impact of early workplace-based return-to-work strategies on work absence duration: a 6-month longitudinal study following an occupational musculoskeletal injury. J Occup Environ Med. 2007;49(9):960-74.

51. Ajzen I. The theory of planned behavior. Organ Behav Human Decis Process. 1991;50:179-211.

52. Linton SJ. The managers role in employees' return to work following back injury. Work Stress. 1991;5(3):189-95.

53. Habeck RV, Hunt HA, VanTol B. Workplace factors associated with preventing and managing work disability. Rehabil Couns Bull. 1998;42:98-143.

54. Arnstein P, Caudill M, Mandle CL, Norris A, Beasley R. Selfefficacy as a mediator of the relationship between pain intensity, disability and depression in chronic pain patients. Pain. 1999;80: 483-91.

55. Ayre M, Tyson GA. The role of self-efficacy and fear avoidance beliefs in the prediction of disability. Aust Psychol. 2001;36(3): $250-3$.

56. Turk DC, Okifuji A. Psychological factors in chronic pain: evolution and revolution. J Consult Clin Psychol. 2002;70(3): 678-90.

57. Meredith P, Strong J, Feeney JA. Adult attachment, anxiety, and pain self-efficacy as predictors of pain intensity and disability. Pain. 2006;123:146-54.

58. Johnson JV, Hall EM. Job strain, work place social support, and cardiovascular disease: a cross-sectional study of a random sample of the Swedish working population. Am J Public Health. 1988;78(10):1336-42.

59. Nieuwenhuijsen K, Verbeek JHAM, de Boer AG, Blonk RW, van Dijk FJ. Supervisory behaviour as a predictor of return to work in employees absent from work due to mental health problems. Occup Environ Med. 2004;61:817-23. 